\title{
Resilience of Sultana (Vitis Vinifera) to Drought and Subsequent Recovery: Field Evaluation of Nine Rootstock Scion Combinations
}

\author{
K J Sommer*, F Hancock and M O Downey \\ Department of Primary Industries Victoria, PO Box 905, Mildura, VIC, 3502, Australia \\ Submitted for publication: May 2010 \\ Accepted for publication: June 2010 \\ Key words: Water deficit, rootstock, drought recovery, Thompson Seedless
}

\begin{abstract}
The work reported here surveyed the recovery of $\mathrm{H} 4$ Sultana from severe drought when grafted to 9 rootstocks (10114 Millardet, 116-60 Lider, 187-24 Lider, 5BB Kober, 1103 Paulsen, Ramsey, 140 Ruggeri, Schwarzmann and selfgrafted Sultana). Vines did not receive any irrigation water from July until late February in the 2007 to 2008 season but were watered normally thereafter to facilitate their recovery. Large differences in leaf retention and fruit yield were apparent among rootstocks just before rewatering and were quantified in order to document the influence of rootstock on vine resilience and the potential for subsequent recovery. Vines grafted to the rootstocks 101-14 Millardet, Schwarzmann and self-grafted Sultana performed poorly during drought and some vines did not recover after re-watering. Vines on other rootstocks retained a viable leaf canopy and showed good potential for recovery. Vines grafted to 187-24 Lider performed best showing high resilience during and good recovery from drought.
\end{abstract}

\section{INTRODUCTION}

A considerable area of vineyards in Sunraysia, situated on the Murray River in north western Victoria, during the 20072008 and the 2008-2009 growing seasons did not receive any or had very little supplementary irrigation because of very low water allocations as a result of ongoing drought. To save water some growers adopted a strategy of taking a proportion of their vineyards out of production by cutting off irrigation during all or part of the growing season. Some did so with the intent of bringing vines back into production in the subsequent season. Interesting questions that arise in this context are how well these vines recover from a prolonged period of often severe water deficit, and how their recovery is affected by the choice of rootstock. The work reported here attempts to provide an initial answer to this question as illustrated for Sultana, a variety in widespread use for wine, table and dried grape production. Historical findings suggest that the ability to withstand drought varies among rootstocks and may greatly influence the drought resilience of the scion (Carbonneau 1985; McCarthy et al., 1997; Whiting, 2004).

\section{MATERIALS AND METHODS}

\section{Site}

The trial site was located near Mildura, Victoria (142.1458 E long., 34.2241 S lat.), one of multiple sites of a former rootstock evaluation experiment conducted by DPI Victoria between 1988 and 2007 (Fletcher, 2001; Downey et al., 2008). The variety was Sultana H4, a high yielding clone when grown under well-watered conditions. The site comprised 10 rows with each row consisting of 9 sub-plots of 3 vines each and was fully randomized within each row. Each of eight of the sub-plots was planted to a different rootstock while one was self-grafted. The following list of rootstocks, including self-grafted Sultana, was evaluated between February 2008 and April 2009.
- 101-14 Millardet (Vitis riparia $\times$ Vitis rupestris)

- 116-60 Lider (Vitis candicans $\times 1613$ C)

- 187-24 Lider (Vitis candicans $\times$ Vitis solonis)

- 5BB Kober (Vitis berlandieri $\times$ Vitis riparia)

- 1103 Paulsen (Vitis berlandieri $\times$ Vitis rupestris)

- Ramsey (Vitis champinii)

- 140 Ruggeri (Vitis berlandieri $\times$ Vitis rupestris)

- Schwarzmann (Vitis riparia $\times$ Vitis rupestris)

- Self-grafted Sultana H4 (Vitis vinifera)

Vines were spaced at $3 \mathrm{~m}$ within and at $4 \mathrm{~m}$ between rows and were trained to a Shaw swing arm trellis (Hayes et al., 1991). The soil was a clay loam to a depth of $115 \mathrm{~cm}$ and a medium clay to a depths of $170 \mathrm{~cm}$. Soil pH at $25 \mathrm{~cm}$ was 8.0 and 9.0 at 115 and $170 \mathrm{~cm}$ respectively. The carbonate content to a depth of $25 \mathrm{~cm}$ was medium ( $0.5-1.5 \%$ alkaline earth) and very high between 25 and $170 \mathrm{~cm}$ depth ( $>8 \%$ alkaline earth). Further details regarding the experimental design, layout, soil description and chemical soil analysis are summarized in Fletcher (2001) and Downey et al. (2008).

The trial vineyard, normally irrigated by full cover under-vine sprinklers, had not received any irrigation from the beginning of the 2007-2008 season in late July until the middle of February of the 2007-2008 season due to a shortfall in water allocations and by mid February vines showed symptoms of severe water stress. The total rainfall for the period between 2007-07-01 and 2008-02-29 was $104 \mathrm{~mm}$ as recorded by a nearby weather station at Mildura airport. After an initial assessment of leaf area retention in mid to late February 2008, and after harvesting the vines, the site was rewatered to field capacity and for the remainder of the season was returned to a regime of weekly irrigations to meet potential vine evapotranspiration, in order to prevent further damage to 


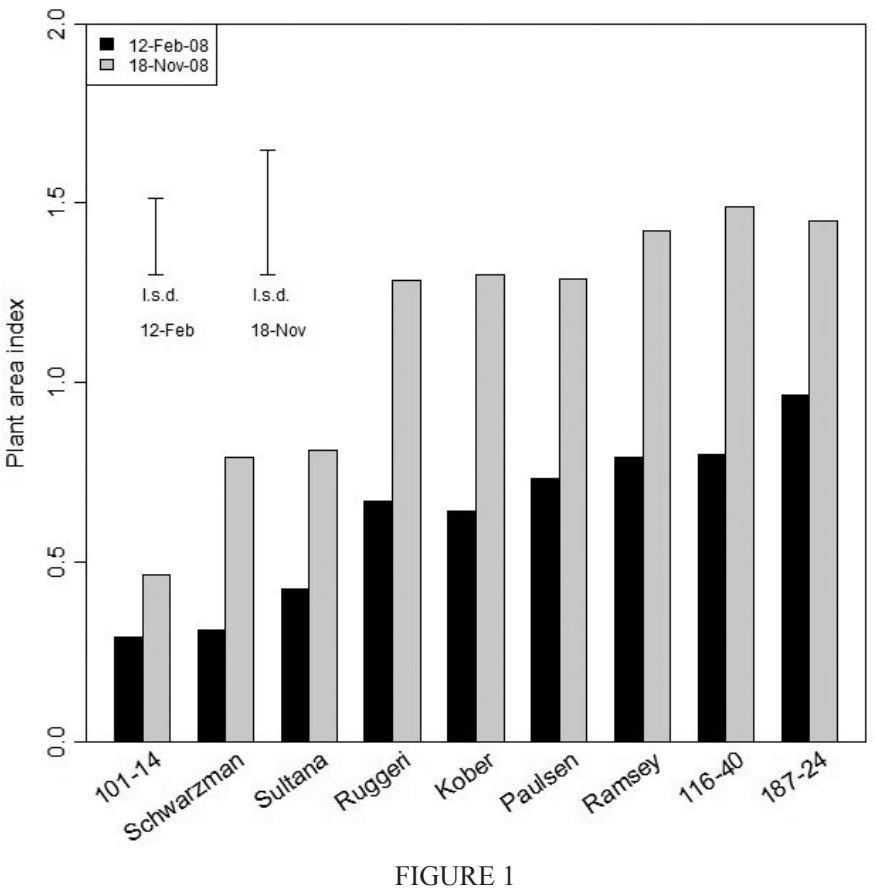

Ranked mean plant area index, an indicator of vine leaf area, recorded on 2008-02-12 and 2008-11-18; vertical bars represent least significant differences (1.s.d. $5 \%$ ).

already severely water stressed vines. In the subsequent season, vines also received a standard irrigation to meet potential vine evapotranspiration (approximately $850 \mathrm{~mm} /$ season).

\section{Measurements}

Estimates of plant area index (PAI) and all other vine based measurements were recorded from the centre vine of each 3 vine plot. The impact of drought on PAI was recorded before rewatering on 2008-02-12, using the LAI-2000 canopy analyser (LI-COR, Inc, 1991) according to the method of Sommer \& Lang (1994). Plant area index is defined as the total surface area of all leaves (both sides), stems, branches and fruit, divided by 2 per unit of ground area. The contribution of the structural vine components (stems and branches) to PAI for the various rootstock scion combinations was more or less constant (approx. 0.25) and differences in PAI were therefore indicative of differences in leaf area retention. On 2008-02-18 fruit of each centre vine was harvested and weighed and bunches were counted. Some bunches had completely desiccated and were weighed separately from those that still had fully turgid berries. Dry weight of the turgid berries was estimated from the recorded fresh weights and sugar level. In the second season (2008-2009) leaf area was again monitored on 2009-10-8 (data not presented) and 2009-11-08. In addition, bunches and shoots were counted on 2009-10-08 to assess the vines' potential for recovery from the drought season. Vines were harvested on 2009-03-19 and fruit of monitored vines was weighed in the field. Fruit was sub-sampled and moisture of each sample was determined in the laboratory using a CALIPO moisture meter (Dried Fruits Association of California). Yields were subsequently normalised to a moisture content of $13 \%$, a standard industry practice in Australia.

\section{Statistical analysis}

Vines growing in or close to the outside rows had a larger plant area index than those growing towards central row positions (data not presented). This was probably due to soil moisture intrusion from the surrounding vineyard which remained on a normal irrigation regime. Consequently, rows numbered 1, 8, 9 and 10 were excluded from further evaluation such that only vines that had not received supplementary irrigation from any source were considered in the final analysis. The remaining replicates (rows 2-7) were analysed as a one-way randomised complete block design. Least Significant Difference test was used to compare rootstock means $(\mathrm{p}<=0.05)$. Statistical analyses and graphing were done in R (R Development Core Team, 2009).

\section{RESULTS}

\section{Leaf area retention in drought and after recovery}

Fig. 1 presents the PAI of each rootstock scion combination ranked in increasing order from left to right, on 2008-02-12, the end of the severe deficit period and after recovery on 2008-1118. Images of each rootstock scion combination in Figs. 2 and 3 further illustrate the degree of leaf retention and recovery following the deficit period.

Leaf retention at the end of the deficit period (Figs. 1 and 2) was very poor for vines grafted to 101-14 Millardet and Schwarzmann. Both were almost completely defoliated by 2008-02-12 and consequently had a PAI near zero. Self-grafted vines also were mostly defoliated but had retained some viable leaves. Vines grafted to Ruggeri, Kober, Paulsen, Ramsey, 116-60 Lider and 187-24 Lider had retained sizable and functional leaf canopies with a larger PAI than vines grafted to either 101-14 Millardet or Schwarzmann.

In the subsequent season following the drought period, plant area index recorded on 2008-11-18 was broadly in line with the ranking recorded at the end of the severe deficit period (Fig. 1). Schwarzmann, 101-14 Millardet and self-grafted vines recovered poorly while all other rootstocks showed good recovery suggesting that vines that retained more leaf in the deficit period also showed better growth in the subsequent season.

\section{Recovery of growth and yield potential after drought}

Shoot and bunch numbers counted in spring are illustrated in Fig. 4 and were broadly in line with those seen for leaf retention and recovery. Vines grafted to 101-14 Millardet and to Schwarzmann either had no or few bunches and few shoots compared to other rootstocks. Self-grafted vines had more shoots than 101-14 Millardet and Schwarzmann. Shoot and bunch number of the remaining rootstock scion combinations was similar with a trend towards greater shoot numbers when grafted to Ramsey, 116-40 Lider and 187-24 Lider relative to Ruggeri, Kober and Paulsen. Generally, results suggest a poor recovery potential for 10114 Millardet and Schwarzmann, a slightly improved potential for self-grafted vines and good recovery potential for the other rootstocks.

\section{Yield performance in drought and after recovery}

Fig. 5 illustrates the yield obtained for each of the rootstock scion combinations on 2008-02-18 after drought and on 2009-03-19 after recovery. Values are ranked from left to right in accordance with the yield recorded on 2009-03-19 at the end of the recovery 


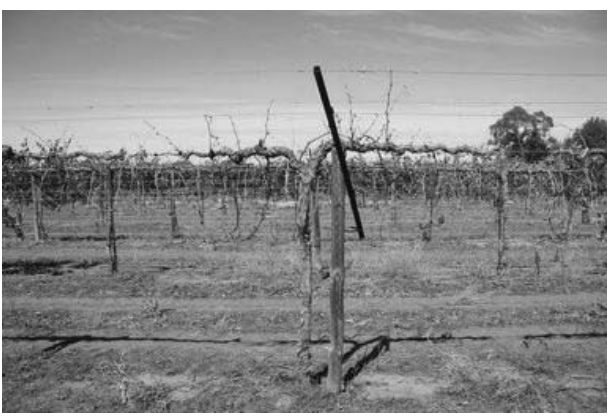

101-14 Millardet

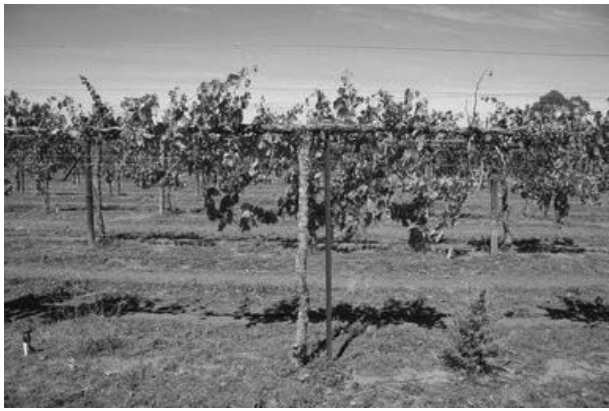

Kober

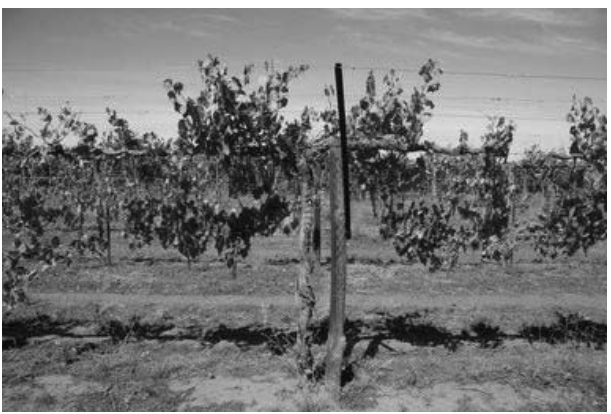

Paulsen

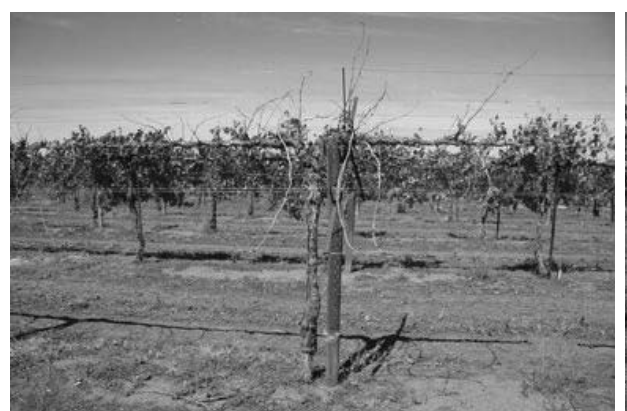

Schwarzmann

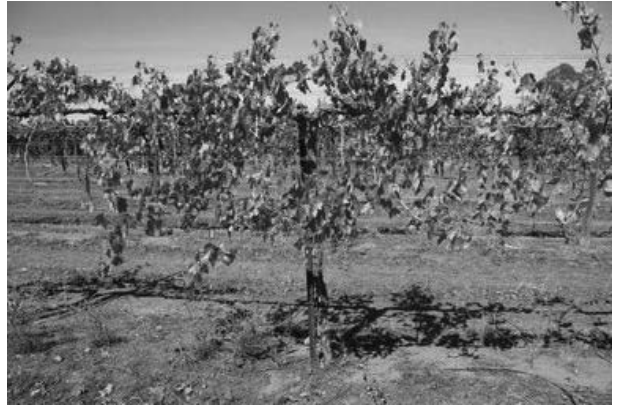

Ruggeri

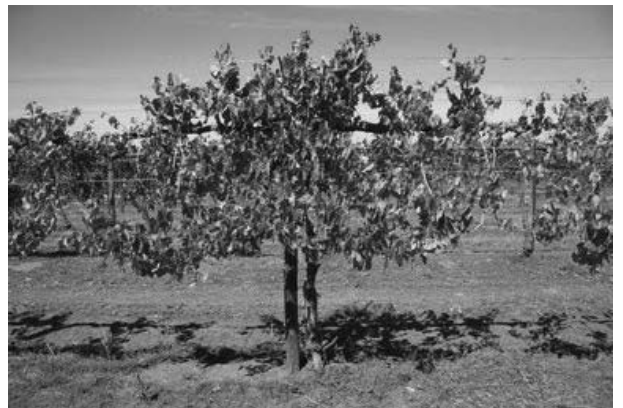

Ramsey

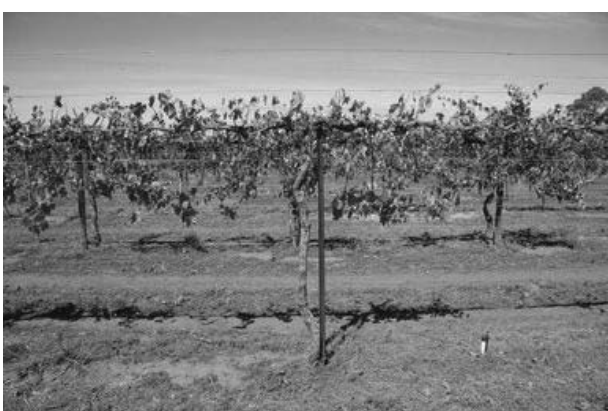

self-grafted (Sultana)

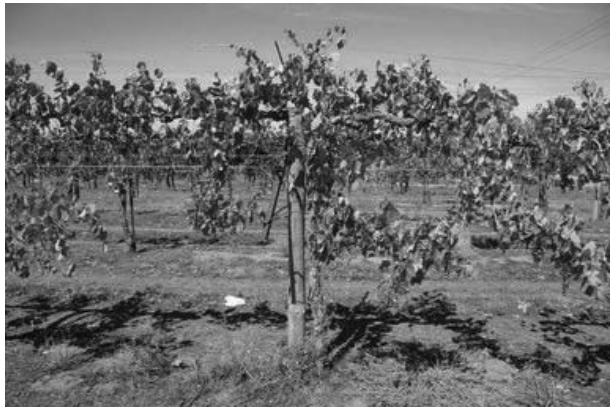

116-60 Lider

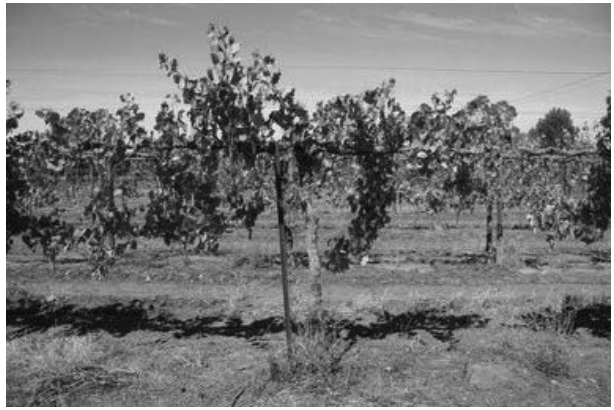

187-24 Lider

FIGURE 2

Images of nine rootstock scion combinations taken on 2008-02-12, at the end of a period of severe water deficit, and ranked according to the retained leaf area for each rootstock.

season. Vines grafed to 187-24, 116-40 and Ramsey had higher yields at the end of the drought period than vines grafted to other rootstocks. After recovery, at the end of the 2008-2009 season, vines grafted to $187-24$ Lider had a much higher yield than all other rootstocks suggesting that its recovery was superior to all other rootstocks.

\section{DISCUSSION}

All rootstocks, except 101-14 Millardet, Schwarzmann and selfgrafted Sultana showed reasonable or high resilience to drought and must have been able to extract sufficient water from the soil to maintain leaf function even under severe water deficit.
Vines grafted to Schwarzmann and 101-14 Millardet showed little resilience suffering almost complete defoliation by the time of harvest and produced negligible fruit yield. Both rootstocks are crosses of $V$. riparia $\times V$. rupestris and their performance is consistent with historical findings of low drought tolerance (Carbonneau, 1985; Nicholas, 1997; Padgett-Johnson et al., 2003). Interestingly, although Kober $5 \mathrm{BB}$ is also a $V$. riparia cross, its scion outperformed Schwarzmann and 101-14 Millardet, suggesting that the specific combination of $V$. riparia and $V$. rupestris conferred a high susceptibility to drought rather than the presence of a $V$. riparia parent per se as is often stated in the literature (Whiting, 2004). 


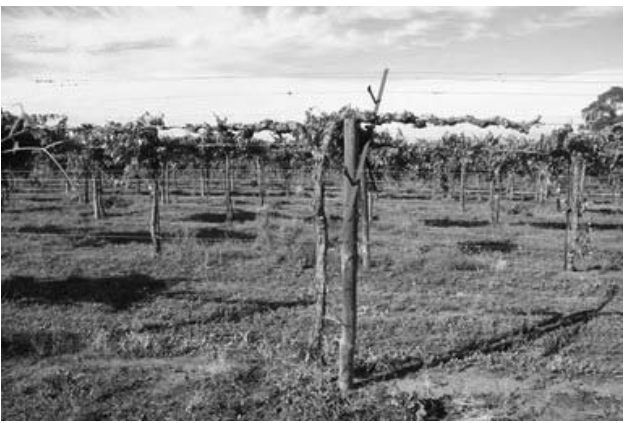

101-14 Millardet

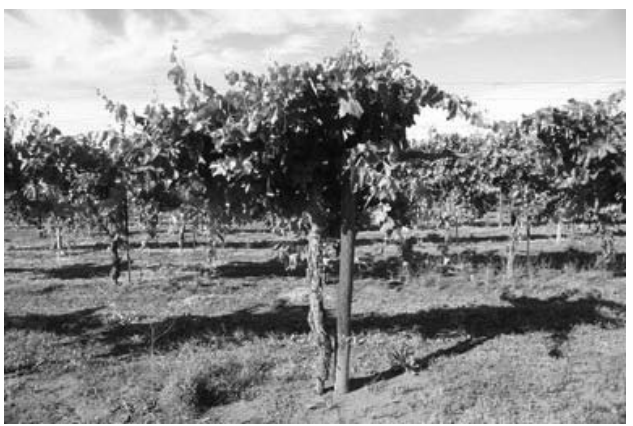

Kober

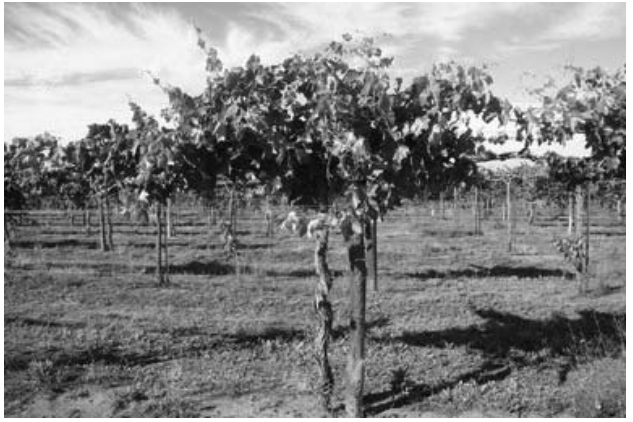

Paulsen

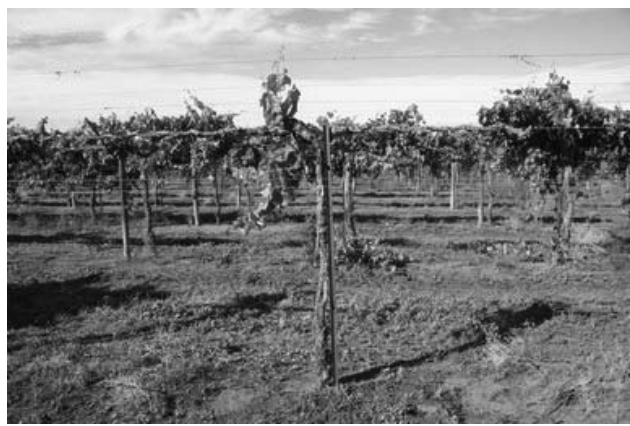

Schwarzmann

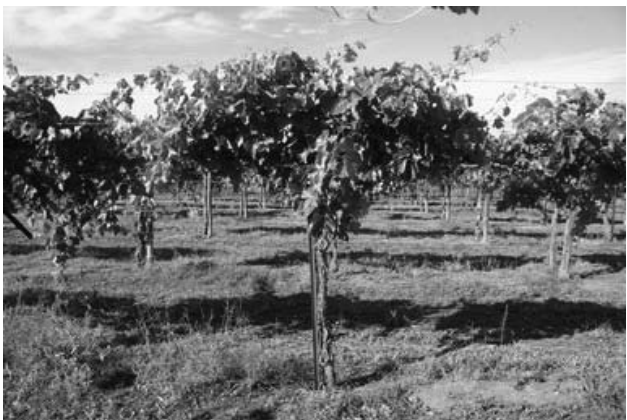

Ruggeri

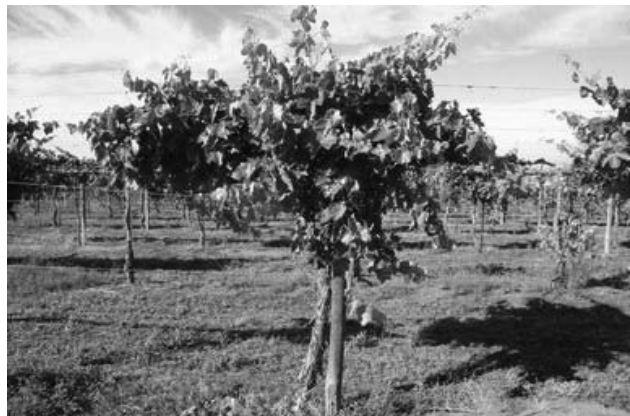

Ramsey

FIGURE 3

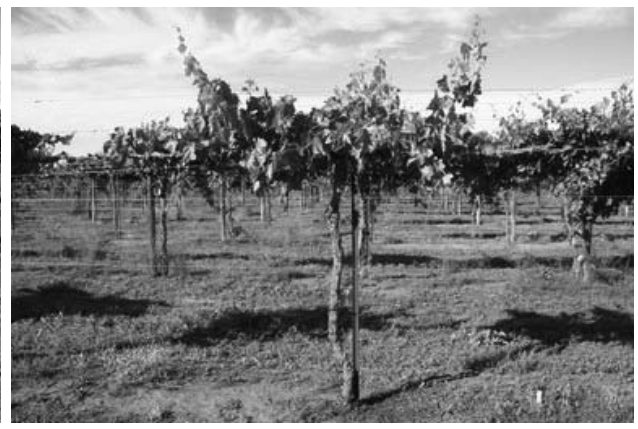

self-grafted (Sultana)

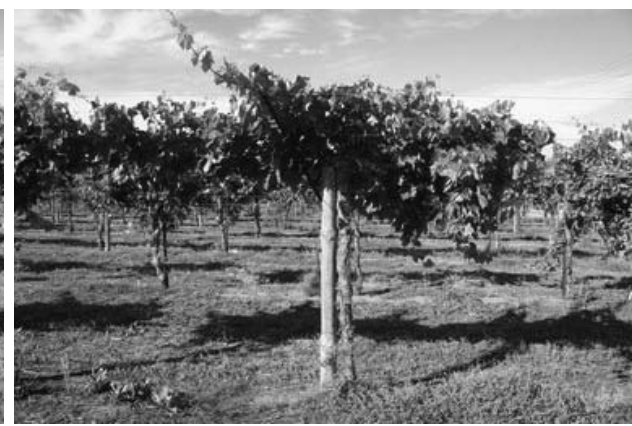

116-60 Lider

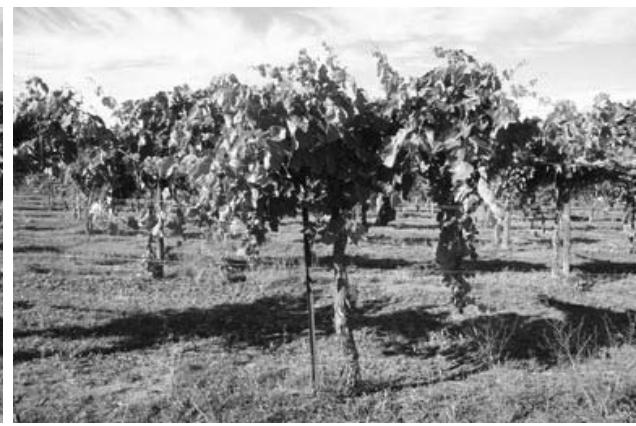

187-24 Lider

Images of nine rootstock scion combinations taken on 2008-11-12 after recovery from a period of severe water deficit and ranked in the same order as in Fig 2.

Those rootstocks arising from crosses with $V$. berlandieri fell into an intermediate group that showed reasonable resilience and recovery although $V$. berlandieri itself has been rated as having a low drought tolerance (Padgett-Johnson et al., 2003). 1103 Paulsen has been shown to confer high drought tolerance (Carbonneau, 1985; Koundouras et al., 2008) but this has been disputed by others (McCarthy et al., 1997).

Ramsey (V. champinii) conferred a high resilience and good recovery probably because of its capacity to develop a deep and extensive root system in soils with a high carbonate content, as was the case in this experiment (Nagarajah, 1987) and its well documented drought tolerance (McCarthy et al., 1997; PadgettJohnson et al., 2003).

Lider 187-24 and 116-40 rootstocks performed similar or better than Ramsey with strong resilience and good recovery. To date there is little historical information on their performance under drought. A number of sources claim that their parentage namely $V$. candicans has high heat and drought tolerance in its native habitat (Hedrick, 1919) although recent work has not confirmed that (Padgett-Johnson et al., 2003).

It is interesting to note that the historical ranking of yield performance of the various rootstock scion combinations that 


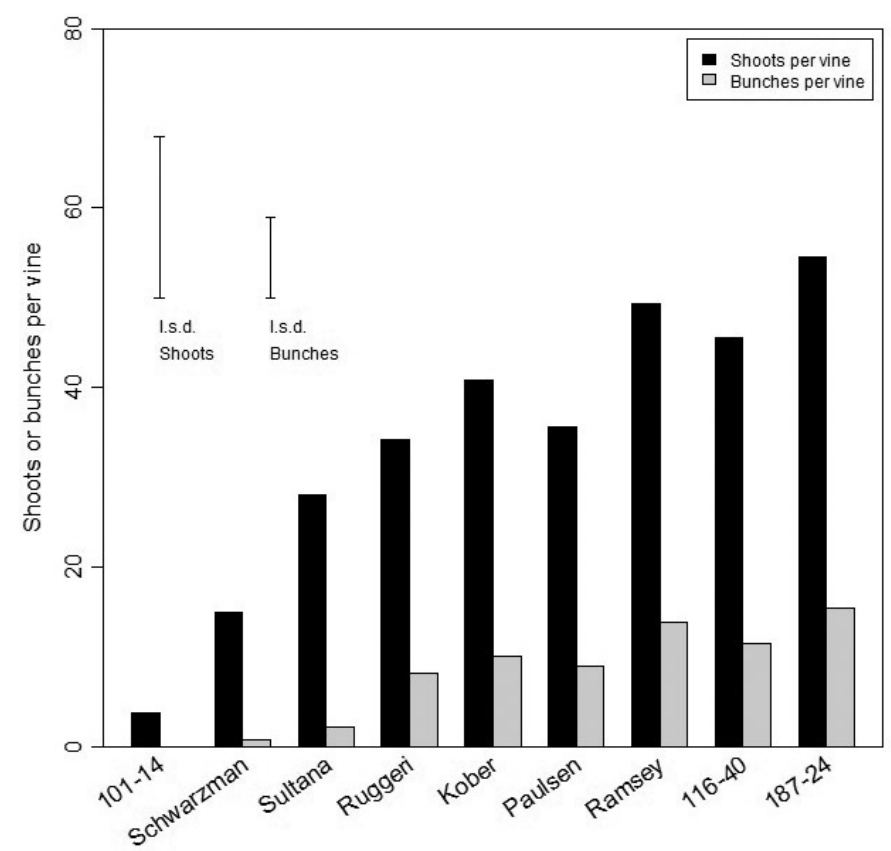

FIGURE 4

Mean shoot and bunch number per vine measured on 2008-10-08; vertical bars represent least significant differences (1.s.d. $5 \%$ ).

formed the basis of the present work and was conducted over a 15 year period under well-watered standard irrigation was not dissimilar to the ranking of the performance in drought and after recovery (Fletcher, 2001; Downey et al., 2008). This suggests that the choice of rootstocks that confer high resilience to drought and subsequent recovery is not necessarily detrimental to high productivity and quality in dried fruit production under well watered conditions.

\section{CONCLUSIONS}

This study demonstrated that rootstock had a strong influence on scion resilience to drought and recovery thereof. Most rootstock scion combinations retained a leaf canopy of sufficient size to produce a crop albeit of little or no commercial value. There was a strong correlation between leaf retention during drought, yield performance at the end of the drought period and recovery in the subsequent season. Careful rootstock selection therefore should be of primary concern for new vineyard establishment or replanting, given the growing uncertainty of a secure water supply in many irrigation regions. The wide range in response to prolonged water deficit suggests good scope in identifying further rootstocks that confer high resilience in periods of severe water deficits. Whether the traits observed in the current work would be conferred to other scions used for wine and table grape production remains yet to be determined.

\section{LITERATURE CITED}

Carbonneau, A., 1985. The early selection of grapevine rootstocks for resistance to drought conditions. Am. J. Enol. Vitic. 36, 195-198.

Downey, M., Pitt, K. \& Hancock, F., 2008. Evaluation of new rootstocks for dried Sultana. Technical report, Department of Primary Industries, Victoria.

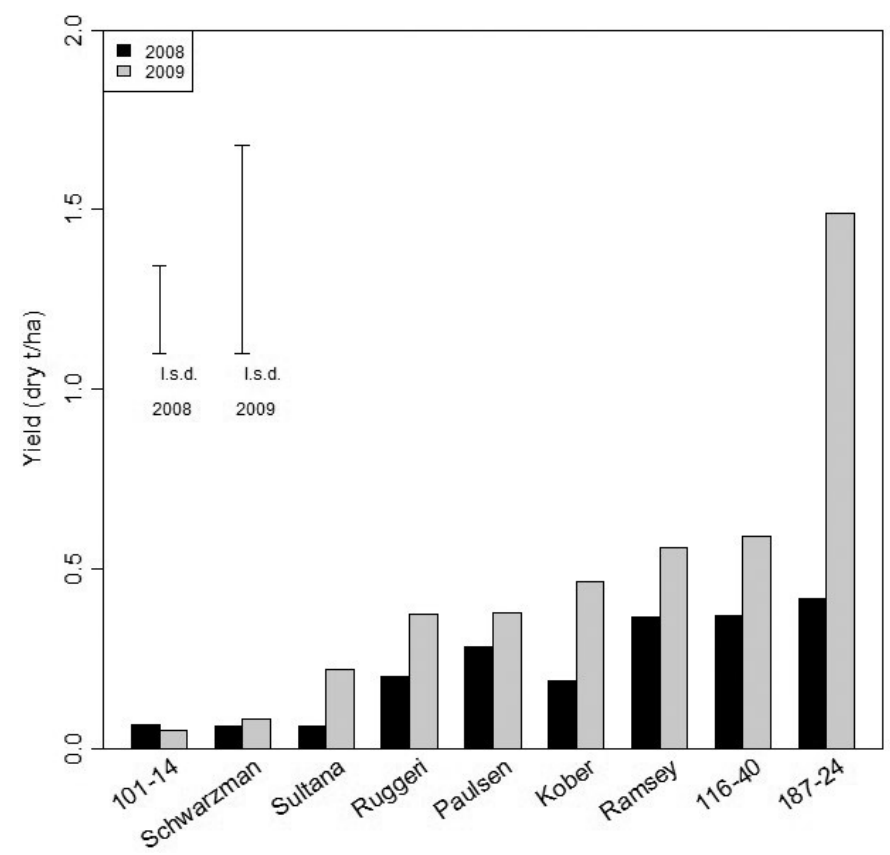

FIGURE 5

Mean yield per rootstock scion combination as recorded on 2008-02-18 and 2009-03-19 and ranked for the latter date; vertical bars represent least significant differences (1.s.d. $5 \%$ ).

Fletcher, G.C., 2001. Evaluation of new rootstocks for dried Sultana, Final Report DAV 81. Technical report, Department of Primary Industries, Victoria.

Hayes, R., Johns, R., Mollah, M. \& Morey, B., 1991. The Shaw Trellis - a new innovation in trellis dried Sultana production. Technical Report Series No 193, Department of Agriculture (Melbourne, Victoria). pp. 1-57.

Hedrick, U., 1919. Manual of American grape-growing. New York Agricultural Experiment Station, The Macmillan Company Edition.

Koundouras, S., Tsialtas, I.T., Zioziou, E. \& Nikolaou, N., 2008. Rootstock effects on the adaptive strategies of grapevine (Vitis vinifera L. cv. Cabernet-Sauvignon) under contrasting water status: Leaf physiological and structural responses. Agric. Ecosyst. Environ. 128, 86-96.

LI-COR, Inc, 1991. LAI-2000 plant canopy analyzer - operating manual. LI-COR, Inc, Lincoln, Nebraska. http://www.licor.com.

McCarthy, M., Cirami, R. \& Furkaliev, D., 1997. Rootstock response of Shiraz Vitis vinifera grapevines to dry and drip-irrigated conditions. Aust. J. Grape Wine Res. 3, 95-98.

Nagarajah, S., 1987. Effect of soil texture on the rooting patterns of Thompson Seedless vines on own roots and on Ramsey rootstocks in irrigated vineyards. Am. J. Enol. Vitic. 38, 54-59.

Nicholas, P., 1997. Rootstock characteristics. Aust. Grapegrower and Winemaker 400,30 .

Padgett-Johnson, M., Williams, L. \& Walker, M., 2003. Vine water relations, gas exchange, and vegetative growth of seventeen Vitis species grown under irrigated and non-irrigated conditions in California. J. Amer. Soc. Hort. Sci. 128, 269-276.

R Development Core Team, 2009. R: A language and environment for statistical computing. R Foundation for Statistical Computing, Vienna, Austria. ISBN 3-900051-07-0.

Sommer, K. \& Lang, A., 1994. Comparative analysis of two indirect methods of measuring leaf area index as applied to minimal and spur pruned grape vines. Aust. J. Plant Physiol. 21, 197-206.

Whiting, J., 2004. Grapevine Rootstocks. In: Dry, P.R. and Coombe, B.G. (eds). Viticulture, vol I, Winetitles, Adelaide. pp. 167-188. 